\title{
Combined effect of silica dust exposure and cigarette smoking on total and cause-specific mortality in iron miners: a cohort study
}

Hanpeng Lai ${ }^{1,2}$, Yuewei Liư ${ }^{3}$, Min Zhou ${ }^{1,2}$, Tingming Shi ${ }^{3}$, Yun Zhou ${ }^{1,2}$, Shaofan Weng ${ }^{4}$ and Weihong Chen ${ }^{1,2^{*}}$

\begin{abstract}
Background: Both cigarette smoking and long-term exposure to crystalline silica dust were reported to be associated with increased mortality. However, the combined effect of both factors has not been well evaluated.

Methods: We investigated a retro-prospective cohort of 7,665 workers from one Chinese iron mine with a median follow-up of 42.8 years. Cumulative silica exposure was estimated for each worker by linking work histories with a job-exposure matrix. Cigarette smoking information was collected through face-to-face questionnaires. Hazard ratios (HRs) for total and cause-specific mortality due to silica exposure and smoking were estimated using Cox proportional hazards models.

Results: A total of 2,814 deaths occurred during 315,772.9 person-years of follow-up. Significantly elevated mortality from all causes, cardiovascular disease, non-malignant respiratory disease and lung cancer was observed among silica-exposed workers, while elevated mortality from non-malignant respiratory disease and lung cancer was observed among smokers. Combined exposure to silica dust and cigarette smoking elevated the proportion of mortality and accounted for 21.2, 76.0, 35.7 and $81.4 \%$ of all causes, non-malignant respiratory disease,

cardiovascular disease, and lung cancer, respectively. Significant additive joint effects of silica exposure and cigarette smoking on mortality from lung cancer (HR $1.893,95 \% \mathrm{Cl} 0.628$ to 3.441$)$ and pneumoconiosis $(6.457,0.725$ to 39.114), together with a significant multiplicative joint effect from all causes $(1.002,1.000$ to 1.004) were observed.

Conclusions: The present findings indicated that silica exposure in combination with cigarette smoking accounted for a fraction of extra deaths in our cohort. Our research showed the urgent need for smoking cessation and silica control among iron miners.
\end{abstract}

Keywords: Cohort, Mortality, Silica, Cigarette smoking, Joint effect

\footnotetext{
* Correspondence: wchen@mails.tjmu.edu.cn

${ }^{1}$ Department of Occupational and Environmental Health, School of Public Health, Tongji Medical College, Huazhong University of Science and Technology, 13 Hangkong Road, Wuhan 430030, Hubei, China ${ }^{2}$ Key Laboratory of Environment and Health, Ministry of Education and Ministry of Environmental Protection, and State Key Laboratory of Environmental Health (Incubating), School of Public Health, Tongji Medical College, Huazhong University of Science and Technology, Wuhan 430030, Hubei, China

Full list of author information is available at the end of the article
}

(c) The Author(s). 2018 Open Access This article is distributed under the terms of the Creative Commons Attribution 4.0 International License (http://creativecommons.org/licenses/by/4.0/), which permits unrestricted use, distribution, and reproduction in any medium, provided you give appropriate credit to the original author(s) and the source, provide a link to the Creative Commons license, and indicate if changes were made. The Creative Commons Public Domain Dedication waiver (http://creativecommons.org/publicdomain/zero/1.0/) applies to the data made available in this article, unless otherwise stated. 


\section{Background}

Crystalline silica is one of the most abundant minerals in the earth's crust and a basic component of sand, soil and granite. Environmental exposure to crystalline silica can occur not only in various natural phenomena such as volcanic explosion and sandstorms but also in agricultural areas and a series of industries, such as metal mining, pottery process, quarrying, construction, and clay manufacturing. Volcanoes and sands are major sources of silica. It has been reported that approximately $9 \%$ of the world's population lives within $100 \mathrm{~km}$ of active volcanoes [1], and more than $30 \%$ of the population has been exposed to sandstorms. In industrial areas, more than 30 million workers have been exposed to silica worldwide [2, 3]. The adverse health effects of silica exposure are an increasing public health concern in recent years $[4,5]$. Long-term exposure to silica dust has been confirmed to be associated with elevated mortality from silicosis, chronic obstructive pulmonary disease (COPD) [6, 7] and other airway diseases, while recent research has further revealed its association with elevated mortality from pulmonary tuberculosis [8, 9], lung cancer [10-12] and cardiovascular disease [3, 13].

Cigarette smoking is a common health problem in the world. According to the World Health Organization, China has approximately 320 million smokers, representing one third of the world's total smokers [14]. Accumulating evidence has suggested that cigarette smoking is associated with increased mortality risks from all causes, malignant neoplasm (especially lung cancer) [15], digestive system tumours [16], ischaemic heart disease [17], and stroke [18]. Published investigations have also reported that the rate of smoking among manual workers was relatively high [19]. In our previous study [20], approximately $64 \%$ workers in metal mines and pottery factories had a history of smoking cigarettes. Based on these facts, consequences due to silica exposure in combination with cigarette smoking need to be explored in detail. However, the joint effect of silica exposure and cigarette smoking on mortality from all causes and specific diseases, especially cardiovascular disease and non-malignant respiratory disease, has not been well evaluated.

Therefore, we presented a retro-prospective cohort study of 7,665 participants from one Chinese iron mine from January 1, 1960 to December 31, 2012. For each participant, cumulative crystalline silica exposure was calculated by linking work histories with a job-exposure matrix since 1950. Cigarette smoking information was collected through questionnaires from self-report and next-of-kin (or colleagues). The objectives of this study were to assess the health effects of silica exposure and cigarette smoking on total and cause-specific mortality and to evaluate the joint effects of silica exposure and cigarette smoking on total and cause-specific mortality.

\section{Methods}

\section{Study population}

This retro-prospective cohort included 7,665 participants who were registered in one iron mine company located in central China and worked for at least 1 year between January 1, 1960 and December 31, 1974. This cohort is one part of the Chinese silica cohort that has been described previously [3, 21]. All participants were followed up until they died, were lost to follow-up, or survived to the end of 2012. Data on personal information and work history were retrospectively collected in 1986, and job information, vital status, cause of death and new diagnosis of pneumoconiosis were prospectively updated yearly until 2012 by industrial hygienists.

\section{Cause of death}

Vital status was traced by local physicians during the follow-up. The cause of death for the deceased was collected from medical records in the hospital (84.45\%), employment registers, accident records or death certificates in the company $(15.34 \%)$, or oral reports from relatives $(0.21 \%)$. The 10 th version of the International Classification of Diseases (ICD-10) was used to code and classified the causes of death into different disease systems.

\section{Silica exposure data}

Monthly measurement of dust concentration in workplaces with silica exposure was required by the Chinese government enforcement system in the early 1950s. A dust monitoring scheme including total dust concentration and crystalline silica content has been conducted by professional staff in iron mines since 1950. Respirable silica concentration in workplaces was then converted from total dust concentration and silica percent in dust particles through a field study [22, 23]. Then, a jobexposure matrix (JEM) with job- and calendar yearspecific silica concentrations was established [3]. The work history for each participant including job titles and work start and end dates was taken from company occupational records. Cumulative respirable silica dust exposure (CDE) for each participant $\left(\mathrm{mg} / \mathrm{m}^{3}\right.$-years) was calculated as Eq. (1):

$$
C D E=\sum_{i=1}^{n}\left(C_{i} \times T_{i}\right)
$$

where $n$ is the total number of job titles, $C$ is the 8 -hweighted mean respirable silica concentration for the $i$ th job title, and $T$ is the duration of working years for the ith job title.

\section{Smoking information}

Detailed smoking data for all participants were first collected in 1986 and updated in 1995, 2004, and 2012. 
Cigarette smoking is defined as having at least 1 cigarette per day for at least 6 months. Smoking information from 728 of the participants $(9.5 \%)$ was provided by their relatives because they either died or withdrew before 1986. Smoking amount was calculated by multiplying packs per day by years of smoking. To examine the reliability of the data, 385 randomly selected subjects were re-investigated in 2004. Agreement on smoking status (never or ever) between next-of-kin and colleagues of decedents was $89.1 \%$, and agreement on smoking status between self-report and next-of-kin (or colleagues) for living subjects was $93.6 \%$ [20].

\section{Statistical analysis}

Based on the distribution of CDE in the entire cohort, we equally divided participants into unexposed, and low, medium, and high silica exposure groups. Cox proportional hazards regression models were used for estimating hazard ratios (HRs) and 95\% confidence intervals (CIs) for total and cause-specific mortality in different silica exposure levels when compared with the unexposed group. Additionally, by fitting the models with $\mathrm{CDE}$ as a continuous variable instead of a categorical one, we determined the correlation between HRs and per one $\mathrm{mg} / \mathrm{m}^{3}$-y increase in CDE. The other covariates were adjusted, including gender, year at hire (five categories, 1955 or earlier, 1956-1960, 1961-1965, 1966-1970, and 1971 or later), age at hire (continuous) and smoking intensity (pack-years, continuous).

The participants who smoked were divided into two groups by median pack-years. We also introduced packyear as a continuous variable to determine the correlation between HRs and per unit increase in pack-years. The other confounding factors, such as gender, year at hire (five categories, 1955 or earlier, 1956-1960, 19611965, 1966-1970, and 1971 or later), age at hire (continuous) and silica exposure (continuous), were adjusted.

The population attributable risks (PARs) were calculated as Eq. (2):

$$
P A R=[P \times(R R-1)] /[P \times(R R-1)+1]
$$

where $P$ is the percentage of exposure among the study population, and $R R$ is the relative risk estimated from $H R$.

To assess the additive joint effects, the relative excess risks due to interaction (RERIs) needed to be evaluated. A linear relative rate model [24] was thus implemented, with the relative risks (RRs) of dichotomized silica exposure and smoking intensity at different levels calculated as Eq. (3):

$$
R R=\left(e^{\wedge} \beta_{0}\right) *\left[1+\beta_{1} A+\beta_{2} B+\beta_{3}(A * B)\right]
$$

where $\beta_{1}$ and $\beta_{2}$ is the excess relative risk per unit of exposure to $\mathrm{A}$ and $\mathrm{B}$, respectively, and $\beta_{3}$ is the departure from additivity of the exposure effects on an relative risk scale. Therefore, $\beta_{3}$ is taken as estimator of RERI.

To assess the multiplicative joint effects, we constructed the Cox regression models by including continuous metrics for both smoking intensity and silica exposure as well as a product term for the interaction of them and determined the HRs. A $p$-value smaller than 0 . 05 was considered statistically significant. All $p$-values were 2-sided. We conducted all data analyses using SAS, version 9.3 software (SAS Inc. Cary, North Carolina).

\section{Results}

A total of 7,665 participants $(6,542$ male, $85.4 \%)$ with median follow-up of 42.8 years were included into analyses. The average participant age upon entry to the cohort was 24.8 years. At the end of follow-up, only 38 (0.5\%) participants were still employed, while 6,519 (85. $0 \%$ ) participants had retired or died, and 1,108 (14.5\%) had left for other companies. Among those who left for other companies, 270 individuals were lost to follow-up, and their person-years were thus truncated at time of loss.

Table 1 shows characteristics of the cohort according to different silica exposure levels. A total of 3,658 (47.7\%) participants were exposed to silica dust during their working period, and $96.2 \%$ of silica-exposed workers were male. The number of smokers (current and former) among all participants and silica-exposed workers were 5,070 (66.1\%) and 2,732 (74.7\%), respectively. The percentage of smokers was $76.9 \%$ for male workers and $3.3 \%$ for female workers. During the follow-up, 2,814 deaths were identified during $315,772.9$ person-years of follow-up. Mortality was 891.2 per 100,000 person-years for all participants. The mortality was 1042.0 per 100,000 person-years and 751.6 per 100,000 person-years among silicaexposed and non-silica-exposed workers, respectively. Among the deaths, 1,581 (56.2\%) were silica-exposed workers, and 1,917 (68.1\%) were smokers.

Annual respirable silica concentrations for different job titles classified by major activity groups from 1950 to 2012 are listed in Fig. 1. The mean respirable silica concentrations ranged from $0.03 \mathrm{mg} / \mathrm{m}^{3}$ to $0.07 \mathrm{mg} / \mathrm{m}^{3}$ before 1978. After taking protection measures, silica concentration fell to between $0.01 \mathrm{mg} / \mathrm{m}^{3}$ and $0.02 \mathrm{mg} / \mathrm{m}^{3}$ from 1978 to 2010 and gradually decreased to below $0.01 \mathrm{mg} / \mathrm{m}^{3}$ in 2012. The silica concentration for the underground mining group was higher than $0.09 \mathrm{mg} / \mathrm{m}^{3}$ in the early 1950 s and then decreased stably. The silica concentration for the ore separation process group was approximately $0.05 \mathrm{mg} / \mathrm{m}^{3}$ before 1969 and became higher than $0.07 \mathrm{mg} / \mathrm{m}^{3}$ between 1970 and 1974 due to adoption of mechanical crushing, and then the concentration decreased to lower than $0.02 \mathrm{mg} / \mathrm{m}^{3}$ after 1975 due to ventilation and wet work. 
Table 1 Basic characteristics of participants $(n=7,665)$ by silica exposure level, 1960-2012

\begin{tabular}{|c|c|c|c|c|c|}
\hline \multirow[t]{2}{*}{ Characteristic } & \multirow{2}{*}{$\begin{array}{l}\text { Entire cohort } \\
(n=7,665)\end{array}$} & \multicolumn{4}{|c|}{ Silica exposure level ${ }^{a}$} \\
\hline & & $\begin{array}{l}\text { Unexposed } \\
(n=4,007)\end{array}$ & $\begin{array}{l}\text { Low } \\
(n=1,218)\end{array}$ & $\begin{array}{l}\text { Medium } \\
(n=1,220)\end{array}$ & $\begin{array}{l}\text { High } \\
(n=1,220)\end{array}$ \\
\hline Male gender $(n, \%)$ & $6542(85.35)$ & $3023(75.44)$ & $1160(95.24)$ & $1181(96.80)$ & $1178(96.56)$ \\
\hline Year at birth & $1939.50 \pm 9.60$ & $1940.23 \pm 9.48$ & $1943.15 \pm 9.08$ & $1938.77 \pm 9.40$ & $1934.15 \pm 8.29$ \\
\hline Year at hire & $1962.28 \pm 7.06$ & $1963.01 \pm 6.83$ & $1965.87 \pm 6.17$ & $1962.06 \pm 6.19$ & $1956.51 \pm 5.94$ \\
\hline Age at hire (years) & $22.78 \pm 5.76$ & $22.78 \pm 5.89$ & $22.72 \pm 5.57$ & $23.29 \pm 5.92$ & $22.36 \pm 5.30$ \\
\hline Ever smoker $(n, \%)^{\mathrm{b}}$ & $5070(66.14)$ & $2338(58.35)$ & $893(73.32)$ & $926(75.90)$ & $913(74.84)$ \\
\hline Never smoker $(n, \%)^{\mathrm{b}}$ & $2595(33.86)$ & $1669(41.65)$ & $325(26.68)$ & $294(24.10)$ & $307(25.16)$ \\
\hline Pack-years of ever smoker ${ }^{b}$ & $28.57 \pm 15.39$ & $28.27 \pm 14.95$ & $26.52 \pm 14.11$ & $29.03 \pm 16.74$ & $30.86 \pm 15.95$ \\
\hline Age at first exposure (years) ${ }^{c}$ & $23.65 \pm 6.36$ & NA & $24.54 \pm 7.27$ & $23.79 \pm 6.09$ & $22.63 \pm 5.44$ \\
\hline Cumulative total dust concentration $\left(\mathrm{mg} / \mathrm{m}^{3}-\mathrm{y}\right)^{\mathrm{c}}$ & $117.95 \pm 70.27$ & NA & $55.21 \pm 21.94$ & $107.32 \pm 18.41$ & $191.22 \pm 67.66$ \\
\hline Average total dust concentration $\left(\mathrm{mg} / \mathrm{m}^{3}\right)^{c}$ & $5.29 \pm 3.02$ & NA & $3.88 \pm 2.49$ & $4.66 \pm 2.05$ & $7.34 \pm 3.22$ \\
\hline Cumulative respirable dust concentration $\left(\mathrm{mg} / \mathrm{m}^{3}-\mathrm{y}\right)^{c}$ & $18.48 \pm 11.01$ & NA & $10.34 \pm 6.53$ & $18.02 \pm 7.03$ & $27.08 \pm 11.46$ \\
\hline Average respirable dust concentration $\left(\mathrm{mg} / \mathrm{m}^{3}\right)^{c}$ & $0.83 \pm 0.47$ & NA & $0.69 \pm 0.47$ & $0.77 \pm 0.37$ & $1.03 \pm 0.50$ \\
\hline Cumulative respirable silica dust concentration $\left(\mathrm{mg} / \mathrm{m}^{3}-\mathrm{y}\right)^{c}$ & $0.83 \pm 0.80$ & NA & $0.34 \pm 0.13$ & $0.66 \pm 0.10$ & $1.51 \pm 1.07$ \\
\hline Average respirable silica dust concentration $\left(\mathrm{mg} / \mathrm{m}^{3}\right)^{c}$ & $0.04 \pm 0.04$ & NA & $0.02 \pm 0.02$ & $0.03 \pm 0.01$ & $0.06 \pm 0.06$ \\
\hline Duration of dust exposure (years) ${ }^{c}$ & $23.95 \pm 9.29$ & NA & $18.12 \pm 9.65$ & $25.55 \pm 7.13$ & $28.17 \pm 7.80$ \\
\hline Pneumoconiosis cases $(n, \%)^{d}$ & $332(9.08)$ & NA & $21(1.72)$ & $79(6.48)$ & $232(19.02)$ \\
\hline Age of first diagnosis of pneumoconiosis (years) ${ }^{d}$ & $49.64 \pm 8.83$ & NA & $51.11 \pm 12.88$ & $50.84 \pm 9.04$ & $49.11 \pm 8.29$ \\
\hline Latency of pneumoconiosis (years) ${ }^{d}$ & $25.60 \pm 8.00$ & NA & $23.67 \pm 9.32$ & $24.69 \pm 7.69$ & $26.08 \pm 7.96$ \\
\hline Age upon entry to cohort (years) & $24.84 \pm 6.73$ & $24.39 \pm 6.61$ & $23.63 \pm 6.18$ & $25.05 \pm 6.67$ & $27.34 \pm 7.09$ \\
\hline Median of follow-up (years) ${ }^{e}$ & $42.75 \pm 12.00$ & $42.34 \pm 14.00$ & $41.92 \pm 5.92$ & $43.09 \pm 10.04$ & $45.34 \pm 14.33$ \\
\hline Deceased $(n, \%)$ & $2814(36.71)$ & $1233(30.77)$ & $401(32.92)$ & $515(42.21)$ & $665(54.51)$ \\
\hline
\end{tabular}

Values were generally presented as mean \pm standard deviation, if not specially indicated

${ }^{a}$ Silica exposure was divided into four levels, i.e. unexposed, low $\left(0.4935 \mathrm{mg} / \mathrm{m}^{3}-\mathrm{y}\right.$ or below), medium $\left(0.4935\right.$ to $\left.0.8423 \mathrm{mg} / \mathrm{m}^{3}-\mathrm{y}\right)$, and high level $\left(0.8423 \mathrm{mg} / \mathrm{m}^{3}-\mathrm{y}\right.$ or above)

${ }^{b}$ Cigarette smoking was defined as taking at least 1 cigarette per day for at least 6 months, and pack-years were calculated only among ever smokers

'Exposure-related results were figured out only among dust-exposed workers

dPneumoconiosis-related results were figured out only among workers diagnosed with pneumoconiosis. Latency of pneumoconiosis was defined as the duration from the onset of dust exposure to the first diagnostic time of pneumoconiosis

eValues hereby were presented as median \pm inter quartile range

$\mathrm{NA}$, i.e. the unavailable values

Table 2 shows the number of deaths and HRs for total and cause-specific mortality due to silica exposure. Malignant neoplasm was the leading cause of death in the iron mine. The second to fourth causes of death in this cohort were cerebrovascular disease, cardiovascular disease, and non-malignant respiratory disease, respectively. Compared with the unexposed group, significantly higher mortality was found in silica-exposed workers from all causes (HR 1.303, 95\% CI 1.206 to 1.408), malignant neoplasm $(1.357,1.173$ to 1.570$)$, cardiovascular disease (1.446, 1.169 to 1.789 ) and non-malignant respiratory disease $(3.166,2.440$ to 4.107$)$. A positive exposure-response relationship was found between (both categorical and continuous) CDE and mortality from all causes, non-malignant respiratory disease (including pneumoconiosis), cardiovascular disease (including pulmonary heart disease), certain infectious and parasitic diseases (including respiratory tuberculosis), and lung cancer. Each $1 \mathrm{mg} / \mathrm{m}^{3}$-y increase in CDE was associated with an 11.7, 41.4, 21.3 and $19.0 \%$ increase in mortality risk from all causes, non-malignant respiratory disease, cardiovascular disease, and lung cancer, respectively. In addition, a positive exposure-response relationship existed between categorical CDE and mortality from ischaemic heart disease, and the HRs were 1.190, 1.538 and 1.781 (monotonically increased) for low, medium and high levels of CDE ( $P$-value for linear trend: < 0.001$)$, respectively, although the relationship between continuous $\mathrm{CDE}$ and mortality was not statistically clear (HR 1.134, 0.990 to 1.298$)$.

Table 3 shows the death number of ever and never smokers and HRs for total and cause-specific mortality due to cigarette smoking. As seen, malignant neoplasm had the largest proportion of ever smokers (77.95\%). When compared with the never smokers, significantly increased mortality risks were found from all causes (HR 


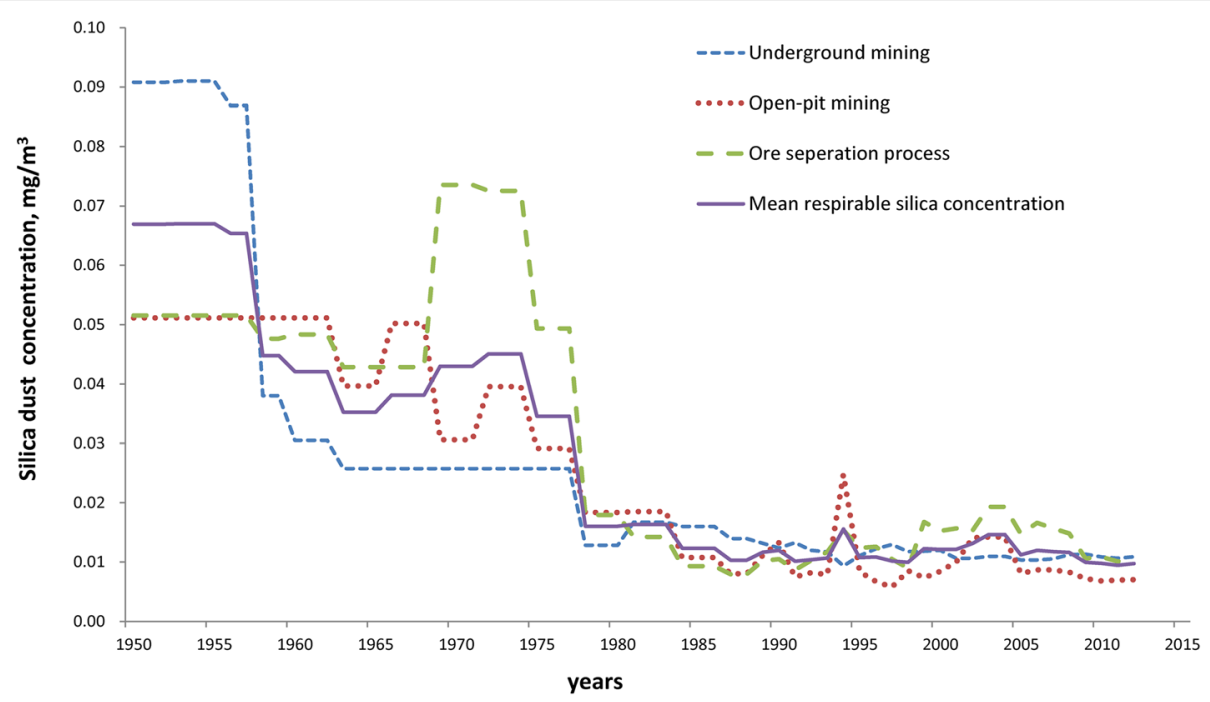

Fig. 1 Annual respirable silica concentration for different job titles, classified by major activity groups, 1950-2012. Horizontal axis represents the year of industrial production and vertical axis represents respirable silica concentration. Solid line represents annual average respirable silica concentration among all the silica-exposed job titles and the other three types of dotted lines represent annual average respirable silica concentration among the specific major activity groups, that is underground mining, open-pit mining and ore separation process group

1.102, 95\% CI 1.008 to 1.205$)$, non-malignant respiratory disease (1.612, 1.229 to 2.115$)$, pulmonary heart disease (2.067, 1.112 to 3.843$)$, malignant neoplasm $(1.694,1.404$ to 2.045 ) and lung cancer $(4.347,2.820$ to 6.700 ) among the smokers, while the increment was not significant from ischaemic heart disease $(1.126,0.823$ to 1.539$)$. A statistically significant exposure-response relationship was found between smoking amount (both categorical and continuous) and mortality from malignant neoplasm (including lung cancer) and non-malignant respiratory disease (including chronic lower respiratory disease). Each 1 pack-year increase in smoking was associated with a $0.7,1.0,0.7$ and $2.3 \%$ increase in the mortality risk from non-malignant respiratory disease, chronic lower respiratory disease, malignant neoplasm and lung cancer, respectively. Furthermore, we found a positive exposureresponse relationship between categorical smoking and mortality from pneumoconiosis with a linear $p$-trend of 0.005 , despite of the fact that the HR for each 1 packyear increase in smoking did not reach statistical significance (HR 1.008, 0.999 to 1.017 ).

After adjustment for potential confounders and smoking, we found that silica exposure accounted for 12.6, $50.8,17.5$ and $24.2 \%$ of mortality from all deaths, nonmalignant respiratory disease, cardiovascular disease, and lung cancer, respectively. Likewise, after adjustment for potential confounders and silica exposure, cigarette smoking accounted for 6.3, 28.8, 12.6 and $68.9 \%$ of mortality from all deaths, non-malignant respiratory disease, cardiovascular disease, and lung cancer, respectively. Eventually, combined exposure to silica dust and cigarette smoking accounted for 21.2, 76.0, 35.7 and 81 .
$4 \%$ of mortality from all deaths, non-malignant respiratory disease, cardiovascular disease, and lung cancer, respectively.

When compared with non-silica-exposed and nonsmoking workers, we found significantly elevated mortality risks from all causes (HR 1.344, 95\% CI 1.189 to 1.520 ), non-malignant respiratory disease $(5.052,3.144$ to 8.116$)$, cardiovascular disease $(1.709,1.214$ to 2.405$)$ and lung cancer $(6.586,3.616$ to 11.992$)$ among silica-exposed and smoking workers. The joint effects of silica exposure and cigarette smoking on total and cause-specific mortality are shown in Table 4. From combined effects analysis, the relative excess risks due to interaction (RERIs) of smoking and silica exposure were 1.893 (95\% CI 0.628 to 3.441) for lung cancer and 6.457 (0.725 to 39.114) for pneumoconiosis, indicating that joint effects were significant and more than additive. The additive joint effects could be further observed without significance for all causes, malignant neoplasm, and non-malignant respiratory disease. A multiplicative interaction between silica exposure and smoking was only significant for all causes $(1.002,1.000$ to 1.004$)$.

\section{Discussion}

In our cohort study of 7,665 workers from one Chinese iron mine, we not only confirmed an exposure-response relationship between long-term exposure to cumulative crystalline silica dust and mortality risk from all causes, non-malignant respiratory disease, cardiovascular disease and lung cancer but also found significant exposureresponse relationships between lifelong cigarette smoking and mortality from non-malignant respiratory disease and 
Table 2 HRs for total and cause-specific mortality associated with silica exposure in the cohort $(n=7,665), 1960-2012$

\begin{tabular}{|c|c|c|c|c|c|c|}
\hline \multirow[t]{2}{*}{ Cause of death (ICD-10) } & \multirow{2}{*}{$\begin{array}{l}\text { Number } \\
\text { of deaths }\end{array}$} & \multirow{2}{*}{$\begin{array}{l}\text { HRs for per } 1 \mathrm{mg} / \\
\mathrm{m}^{3}-\mathrm{y} \text { increase in } \\
\mathrm{CDE}\end{array}$} & \multicolumn{4}{|c|}{ HRs for silica exposure levels versus unexposed ${ }^{a}$} \\
\hline & & & Low & Medium & High & $p$-Value ${ }^{b}$ \\
\hline Malignant neoplasm (CO0-C97) & 789 & $1.048(0.962,1.142)$ & $1.531(1.241,1.890)$ & $1.378(1.137,1.669)$ & $1.238(1.025,1.494)$ & 0.009 \\
\hline Malignant neoplasm of oesophagus (C15) & 66 & $0.952(0.693,1.307)$ & $1.335(0.648,2.753)$ & $1.511(0.795,2.874)$ & $1.249(0.644,2.420)$ & 0.384 \\
\hline Malignant neoplasm of stomach (C16) & 104 & $1.130(0.931,1.373)$ & $1.980(1.153,3.401)$ & $1.380(0.800,2.379)$ & $1.367(0.814,2.295)$ & 0.223 \\
\hline $\begin{array}{l}\text { Malignant neoplasm of liver and } \\
\text { intrahepatic bile ducts (C22) }\end{array}$ & 152 & $0.774(0.585,1.025)$ & $1.512(0.972,2.353)$ & $1.060(0.681,1.648)$ & $0.774(0.487,1.229)$ & 0.359 \\
\hline Lung cancer (C33-C34) & 262 & $1.190(1.049,1.349)$ & $1.671(1.132,2.466)$ & $1.663(1.193,2.318)$ & $1.671(1.216,2.298)$ & 0.001 \\
\hline $\begin{array}{l}\text { Certain infectious and parasitic diseases } \\
\text { (A00-B99, J65) }\end{array}$ & 89 & $1.204(1.018,1.423)$ & $1.073(0.520,2.212)$ & $1.560(0.882,2.761)$ & $1.790(1.064,3.010)$ & 0.020 \\
\hline Respiratory tuberculosis (A15-A16, J65) & 58 & $1.226(1.017,1.477)$ & $0.523(0.153,1.785)$ & $1.459(0.695,3.061)$ & $2.532(1.383,4.635)$ & 0.002 \\
\hline Cardiovascular disease (100-152, 170-199) & 372 & $1.213(1.117,1.318)$ & $0.986(0.672,1.447)$ & $1.373(1.030,1.831)$ & $1.723(1.345,2.206)$ & $<0.001$ \\
\hline Ischaemic heart disease (I20-125) & 219 & $1.134(0.990,1.298)$ & $1.190(0.738,1.918)$ & $1.538(1.063,2.226)$ & $1.781(1.281,2.476)$ & $<0.001$ \\
\hline Pulmonary heart disease (I26-127) & 66 & $1.352(1.197,1.529)$ & $0.562(0.168,1.880)$ & $1.258(0.615,2.573)$ & $2.009(1.160,3.479)$ & 0.010 \\
\hline Cerebrovascular disease (160-169) & 388 & $0.973(0.859,1.103)$ & $0.950(0.670,1.345)$ & $1.234(0.945,1.613)$ & $0.945(0.724,1.233)$ & 0.995 \\
\hline Disease of the respiratory system (J00-J99) & 324 & $1.414(1.329,1.505)$ & $2.817(1.927,4.118)$ & $2.714(1.954,3.768)$ & $3.615(2.718,4.807)$ & $<0.001$ \\
\hline Pneumoconiosis (J60-J65) & 110 & $1.384(1.255,1.525)$ & 1.000 (reference) & $2.245(0.912,5.524)$ & $5.312(2.298,12.280)$ & $<0.001$ \\
\hline Chronic lower respiratory disease (J40-J47) & 142 & $1.264(1.115,1.434)$ & $2.759(1.688,4.507)$ & $2.060(1.304,3.253)$ & $1.720(1.106,2.675)$ & 0.012 \\
\hline Disease of the digestive system (K00-K93) & 95 & $0.877(0.635,1.211)$ & $1.467(0.831,2.587)$ & $1.065(0.605,1.874)$ & $0.838(0.468,1.499)$ & 0.629 \\
\hline Fibrosis and cirrhosis of liver (K74) & 63 & $0.770(0.487,1.218)$ & $1.302(0.651,2.601)$ & $1.079(0.549,2.121)$ & $0.714(0.335,1.524)$ & 0.488 \\
\hline $\begin{array}{l}\text { External causes of morbidity and mortality } \\
\text { (V01-Y98) }\end{array}$ & 193 & $0.883(0.702,1.110)$ & $2.839(1.996,4.038)$ & $1.145(0.745,1.761)$ & $0.928(0.591,1.458)$ & 0.953 \\
\hline All diseases (A00-Y98) & 2814 & $1.117(1.074,1.162)$ & $1.368(1.218,1.537)$ & $1.246(1.121,1.383)$ & $1.313(1.192,1.447)$ & $<0.001$ \\
\hline
\end{tabular}

HRs were calculated by using Cox proportional hazards models, which included the duration of follow-up as time variable and were adjusted for gender, year at hire (five categories: 1955 or earlier, 1956-1960, 1961-1965, 1966-1970, 1971 or later), age at hire (continuous), and smoking intensity (continuous). Pneumoconiosis mortality risks were estimated only among silica-exposed workers

${ }^{a}$ The categorical analyses were conducted on the basis of various silica exposure level, i.e. unexposed, low ( $0.4935 \mathrm{mg} / \mathrm{m}^{3}$-y or below), medium ( 0.4935 to 0.8423 $\left.\mathrm{mg} / \mathrm{m}^{3}-\mathrm{y}\right)$, and high level $\left(0.8423 \mathrm{mg} / \mathrm{m}^{3}-\mathrm{y}\right.$ or above). The reference category was defined as the unexposed level, except pneumoconiosis, which used low level as reference category

${ }^{\mathrm{b}}$ Evaluated by including the median exposure values within each exposure level as a continuous variable in the model

lung cancer. Furthermore, we observed significant additive joint effects of silica exposure and cigarette smoking on mortality from lung cancer and pneumoconiosis, together with a significant multiplicative joint effect from all causes.

A significant positive exposure-response relationship was found between CDE and mortality from all causes, non-malignant respiratory disease, respiratory tuberculosis, and cardiovascular disease among 74,040 Chinese workers in our previous analysis [3]. In the present study, we extended 10 years of follow-up for all participants from one iron mine of the above cohort. At the end of follow-up, only $0.5 \%$ participants of this cohort were still working. In other words, we completed the entire follow-up of lifetime occupational exposure to silica dust for more than $99 \%$ participants and could therefore provide reliable evaluations about adverse health effects from silica exposure. Our cohort reconfirmed an obvious exposure-response relationship between silica exposure and mortality from all causes, non-malignant respiratory disease, cardiovascular disease, and lung cancer.
Consistent with our study, research at an iron ore mine in Cumbria showed significantly elevated standardized mortality ratios (SMRs) from all causes (1.27), neoplasm (1.18), ischaemic heart disease (1.18), and respiratory disease (1.73) [25]. Another iron ore mine cohort study in Sweden with 5 years of follow-up reported significantly elevated mortality risks from all causes (SMR $1.05,95 \%$ CI 1.02 to 1.09$)$, lung cancer $(1.73,1.52$ to 1.97$)$, respiratory disease $(1.14,1.00$ to 1.28$)$, and myocardial infarction (1.12, 1.07 to 1.18) [26]. However, a retrospective research from a Minnesota haematite cohort did not find any excess death rates from all causes or respiratory disease, which might be due to insufficient control for smoking or potential interference from other unknown types of productive dusts [27].

As a serious public health concern, smoking contributes to increased mortality from cardiovascular disease, respiratory disease and malignant neoplasm. Our study strongly demonstrated the exposure-response relationship between smoking amount and mortality from nonmalignant respiratory disease and lung cancer, two main 
Table 3 HRs for total and cause-specific mortality associated with cigarette smoking in the cohort $(n=7,665), 1960-2012$

\begin{tabular}{|c|c|c|c|c|c|}
\hline \multirow[t]{2}{*}{ Cause of death (ICD-10) } & \multirow{2}{*}{$\begin{array}{l}\text { Ever/Never } \\
\text { smokers }\end{array}$} & \multirow{2}{*}{$\begin{array}{l}\text { HR for per } 1 \text { pack-year } \\
\text { increase in smoking }\end{array}$} & \multicolumn{3}{|c|}{ HRs for smoking intensity versus non-smoking ${ }^{a}$} \\
\hline & & & $<26.08$ pack-years & $\geq 26.08$ pack-years & $p$-trend ${ }^{b}$ \\
\hline Malignant neoplasm (CO0-C97) & $615 / 174$ & $1.007(1.004,1.011)$ & $1.689(1.364,2.090)$ & $1.698(1.392,2.072)$ & $<0.001$ \\
\hline Malignant neoplasm of oesophagus (C15) & $46 / 20$ & $0.997(0.984,1.010)$ & $0.944(0.487,1.827)$ & $0.979(0.535,1.790)$ & 0.956 \\
\hline Malignant neoplasm of stomach (C16) & $72 / 32$ & $0.990(0.979,1.001)$ & $1.207(0.746,1.952)$ & $0.617(0.372,1.022)$ & 0.050 \\
\hline $\begin{array}{l}\text { Malignant neoplasm of liver and intrahepatic } \\
\text { bile ducts (C22) }\end{array}$ & $120 / 32$ & $0.991(0.982,1.000)$ & $2.142(1.379,3.326)$ & $0.968(0.609,1.538)$ & 0.511 \\
\hline Lung cancer (C33-C34) & $228 / 34$ & $1.023(1.019,1.028)$ & $1.883(1.111,3.192)$ & $6.115(3.908,9.570)$ & $<0.001$ \\
\hline Certain infectious and parasitic diseases (A00-B99, J65) & $62 / 27$ & $0.982(0.970,0.995)$ & $1.504(0.893,2.533)$ & $0.633(0.358,1.122)$ & 0.097 \\
\hline Respiratory tuberculosis (A15-A16, J65) & $43 / 15$ & $0.991(0.976,1.005)$ & $1.756(0.889,3.471)$ & $1.009(0.503,2.025)$ & 0.905 \\
\hline Cardiovascular disease (100-152, 170-199) & 259/113 & $1.002(0.997,1.007)$ & $1.546(1.178,2.029)$ & $1.012(0.774,1.324)$ & 0.885 \\
\hline Ischaemic heart disease (120-125) & $150 / 69$ & $1.005(0.998,1.011)$ & $1.173(0.810,1.699)$ & $1.097(0.782,1.539)$ & 0.632 \\
\hline Pulmonary heart disease (I26-127) & $51 / 15$ & $1.007(0.995,1.019)$ & $3.097(1.608,5.965)$ & $1.365(0.675,2.760)$ & 0.507 \\
\hline Cerebrovascular disease (160-169) & $258 / 130$ & $5,1.005)$ & $.801,1.389)$ & $0.973(0.757,1.249)$ & 0.797 \\
\hline Disease of the respiratory system (J00-J99) & $246 / 78$ & $1.007(1.002,1.012)$ & $1.473(1.068,2.031)$ & $1.701(1.275,2.268)$ & $<0.001$ \\
\hline Pneumoconiosis (J60-J65) & $93 / 17$ & $1.008(0.999,1.017)$ & $2.928(1.638,5.237)$ & $2.458(1.394,4.334)$ & 0.005 \\
\hline Chronic lower respiratory disease (J40-J47) & $104 / 38$ & $1.010(1.002,1.017)$ & $1.058(0.633,1.768)$ & $1.745(1.143,2.665)$ & 0.006 \\
\hline Disease of the digestive system (K00-K93) & $63 / 32$ & $0.978(0.966,0.990)$ & $1.369(0.843,2.223)$ & $0.380(0.212,0.684)$ & 0.001 \\
\hline Fibrosis and cirrhosis of liver (K74) & $42 / 21$ & $0.975(0.960,0.991)$ & $1.305(0.721,2.362)$ & $0.360(0.174,0.748)$ & 0.006 \\
\hline External causes of morbidity and mortality (V01-Y98) & $120 / 73$ & $0.960(0.950,0.970)$ & $0.980(0.706,1.360)$ & $0.262(0.170,0.405)$ & $<0.001$ \\
\hline All diseases (A00-Y98) & $1917 / 897$ & $1.001(0.999,1.003)$ & $1.176(1.060,1.305)$ & $1.056(0.958,1.163)$ & 0.413 \\
\hline
\end{tabular}

HRs were calculated by using Cox proportional hazards models, which included the duration of follow-up as time variable and were adjusted for gender, year at hire (five categories: 1955 or earlier, 1956-1960, 1961-1965, 1966-1970, 1971 or later), age at hire (continuous), and silica exposure (pack-years, continuous). Pneumoconiosis mortality risks were estimated only among silica-exposed workers

${ }^{a}$ The categorical analyses were conducted on the basis of smoking intensity, including non-smoking, $<26.08$ pack-years and $\geq 26.08$ pack-years, with 26.08 pack-years as the median point for smoking intensity. The reference category was defined as the non-smoking level

${ }^{\mathrm{b}}$ Evaluated by including the median exposure values within each smoking intensity category as a continuous variable in the model

causes of death occupying the top rank in much of the current smoking research worldwide. The World Health Organization estimated that approximately 100 million people died of smoking across the twentieth century [28]. In addition, according to the Surgeon General's Report in 2014 [29], smoking causes one of every three deaths from cardiovascular disease. In our study, an increase in mortality from cardiovascular disease (including ischaemic and pulmonary heart disease) was also observed among smokers when compared with non-smokers.

A large amount of research has testified to the influence of smoking on mortality. According to 50 years of observational research on British male doctors, the excess mortality associated with cigarette smoking was elevated for men born before $1900(\mathrm{SMR}=1.16)$ and peaked for men born in the 1920s $(\mathrm{SMR}=2.83)$. The probabilities of dying in middle age were 42 and $24 \%$ among smokers and non-smokers (a 2-fold mortality ratio) for those born in the 1910 s, and $43 \%$ vs $15 \%$ (a $3-$ fold mortality ratio) for those born in the 1920s, respectively [30]. A cohort study in New Zealand also reported that the relative effect of smoking on mortality differed over time [31]. Additionally, a pooled study provided 2fold and 1.3-fold excess mortality for current and former smokers compared with those who never smoked, and the excess mortality decreased with time since cessation of smoking [32].

Smoking acts as an essential inducing factor for lung cancer and non-malignant respiratory disease on its own, just as our research suggested. In addition, smoking, especially cigarette smoking, modifies the relationship between silica exposure and mortality from lung cancer and non-malignant respiratory disease. Because of the inherent toxicity and carcinogenicity of cigarettes [33], the adverse health effects due to combined exposure to silica dust and cigarette smoking are strengthened to some extent. In our previous research with 34,018 workers over 44 years of follow-up [20], a joint effect of occupational silica exposure and cigarette smoking on mortality from lung cancer was discovered to be greater than additive models (RERI $0.98,0.23$ to 1.74 ) and very close to multiplicative models (interaction term 1.27, 0.75 to 2.15). Similar results were also reported from a pooled analysis in Canada, which discovered that joint effects of silica exposure and smoking were 
Table 4 Estimated HRs for mortality, associated with combined exposure to silica and smoking ( $n=7,665), 1960-2012$

\begin{tabular}{|c|c|c|c|c|}
\hline \multirow{2}{*}{$\begin{array}{l}\text { Cause of death } \\
\text { (ICD-10) }\end{array}$} & \multicolumn{2}{|c|}{ Hazard ratio and 95\% confidence interval } & \multirow{2}{*}{$\begin{array}{l}\text { Interaction effect for } \\
\text { additivity (RERI) }\end{array}$} & \multirow{2}{*}{$\begin{array}{l}\text { Interaction factor on } \\
\text { multiplicative scale }\end{array}$} \\
\hline & Unexposed workers & Exposed workers & & \\
\hline \multicolumn{5}{|c|}{ Malignant neoplasm (C00-C97) } \\
\hline Never smokers & 1.000 (reference) & $1.271(0.923,1.748)$ & \multirow[t]{2}{*}{$0.306(-0.306,0.835)$} & \multirow[t]{2}{*}{$0.999(0.995,1.004)$} \\
\hline Ever smokers & $1.602(1.212,2.119)$ & $2.196(1.679,2.871)$ & & \\
\hline \multicolumn{5}{|c|}{ Lung cancer (C33-C34) } \\
\hline Never smokers & 1.000 (reference) & $1.460(0.698,3.051)$ & \multirow[t]{2}{*}{$1.893(0.628,3.441)$} & \multirow{2}{*}{$0.999(0.993,1.005)$} \\
\hline Ever smokers & $3.840(2.079,7.094)$ & $6.586(3.616,11.992)$ & & \\
\hline \multicolumn{5}{|c|}{ Cardiovascular disease (100-152, 170-199) } \\
\hline Never smokers & 1.000 (reference) & $1.445(0.979,2.132)$ & \multirow[t]{2}{*}{$-0.237(-1.062,0.381)$} & \multirow[t]{2}{*}{$1.002(0.997,1.007)$} \\
\hline Ever smokers & $1.190(0.828,1.711)$ & $1.709(1.214,2.405)$ & & \\
\hline \multicolumn{5}{|c|}{ Ischaemic heart disease (120-125) } \\
\hline Never smokers & 1.000 (reference) & $1.487(0.900,2.455)$ & \multirow[t]{2}{*}{$-0.144(-1.196,0.592)$} & \multirow[t]{2}{*}{$1.005(0.998,1.013)$} \\
\hline Ever smokers & $1.049(0.651,1.690)$ & $1.690(1.083,2.635)$ & & \\
\hline \multicolumn{5}{|c|}{ Disease of the respiratory system (J00-J99) } \\
\hline Never smokers & 1.000 (reference) & $3.488(2.095,5.808)$ & \multirow[t]{2}{*}{$0.136(-1.784,1.633)$} & \multirow[t]{2}{*}{$1.002(0.998,1.006)$} \\
\hline Ever smokers & $1.679(0.996,2.828)$ & $5.052(3.144,8.116)$ & & \\
\hline \multicolumn{5}{|c|}{ Pneumoconiosis $(\mathrm{J} 60-\mathrm{J} 65)^{\mathrm{a}}$} \\
\hline Never smokers & 1.000 (reference) & $3.319(0.757,14.560)$ & \multirow[t]{2}{*}{$6.457(0.725,39.114)$} & \multirow[t]{2}{*}{$1.003(0.996,1.009)$} \\
\hline Ever smokers & $1.973(0.429,9.067)$ & $8.658(2.110,35.530)$ & & \\
\hline \multicolumn{5}{|c|}{ Chronic lower respiratory disease (J40-J47) } \\
\hline Never smokers & 1.000 (reference) & $3.200(1.566,6.536)$ & \multirow[t]{2}{*}{$-1.170(-4.236,0.488)$} & \multirow[t]{2}{*}{$1.000(0.993,1.008)$} \\
\hline Ever smokers & $2.142(1.057,4.341)$ & $3.725(1.901,7.301)$ & & \\
\hline \multicolumn{5}{|l|}{ All diseases (A00-Y98) } \\
\hline Never smokers & 1.000 (reference) & $1.139(0.989,1.313)$ & \multirow[t]{2}{*}{$0.158(-0.136,0.421)$} & \multirow[t]{2}{*}{$1.002(1.000,1.004)$} \\
\hline Ever smokers & $0.977(0.858,1.113)$ & $1.344(1.189,1.520)$ & & \\
\hline \multicolumn{5}{|c|}{$\begin{array}{l}\text { HRs were calculated by using Cox proportional hazards models, which included the durations of follow-up as time variables and were adjusted for gender, year at } \\
\text { hire (five categories: } 1955 \text { or earlier, 1956-1960, 1961-1965, 1966-1970, } 1971 \text { or later), age at hire (continuous) } \\
\text { The dichotomous analyses were conducted on the basis of silica exposure (unexposed or exposed) and smoking status (never of ever), and the reference category } \\
\text { was defined as the non-silica-exposed and non-smoking level, except pneumoconiosis } \\
\text { aFor pneumoconiosis, the dichotomous analysis was conducted on the basis of silica exposure (lower or higher level divided by } 0.65328 \mathrm{mg} / \mathrm{m}^{3} \text {-y) and smoking } \\
\text { status (never of ever), and the reference category was defined as the lower-silica-exposed and non-smoking level } \\
\text { bInteraction effects were not statistically significant, unless } 0 \text { was included into the confidence intervals of relative excess risk due to interaction (RERI), or } 1 \text { was } \\
\text { included into the confidence intervals of interaction factor on multiplicative scales }\end{array}$} \\
\hline
\end{tabular}

between additive and multiplicative models, perhaps closer to the latter [34]. Our present study provided obvious results again for lung cancer, confirming a joint effect far beyond additive models (RERI 1.893, 0.628 to 3.441) and approaching multiplicative models (interaction term $0.999,0.993$ to 1.005 ). The significant additive joint effect of silica and cigarettes for lung cancer can be explained by the synergy of cigarette-induced genetic and cellular toxicity [33] and the silica-induced pulmonary inflammation and fibrosis [35].

Further, our research evaluated potential joint effects of silica exposure and smoking on mortality from other diseases. Significant additive interactions were observed on the mortality from lung cancer and pneumoconiosis, and a significant multiplicative interaction was found on the mortality from all causes. The analysis of population attributable risks (PARs) provided similar results, where combined exposure to silica dust and cigarette smoking accounted for elevated proportions of mortality from all causes, non-malignant respiratory disease, cardiovascular disease, and lung cancer compared with exposure to silica dust or cigarette smoking alone. Published literature has also suggested that persistent inflammation induced by silica dust may be related to health damage not only from lungs [36] but also from kidney, heart and liver [5]. On the other hand, cigarette smoking may exacerbate persistent toxicity and inflammation induced by silica exposure.

This study has several advantages. First, the cohort is large with a long period of follow-up and a low rate of withdrawal. Second, detailed data on dust concentration 
from the workplace and personal work history were acquired to estimate cumulative respirable silica exposure for each participant. Moreover, we have collected detailed and accurate smoking data for each participant.

One limitation of this study is that the silica concentration before 1950 was estimated using the concentration in 1950, which might lead to underestimated exposure for workers who started working before 1950 (140 workers). However, the results did not change after excluding the participants who started work before 1950 . Another limitation is that cigarette smoking data for the deceased derived from their colleagues or next-of-kin, and recall bias might exist as a consequence. Lastly, the healthy worker survivor effect might underestimate risk of mortality from total and specific causes. Nevertheless, the results did not change substantially when we put the duration of employment into the regression models to re-analyse mortality risks with regard to silica, smoking and their combined effects.

\section{Conclusions}

In this cohort study of an iron mine, we confirmed adverse health effects of long-term crystalline silica exposure and life-long cigarette smoking. The joint effects of silica exposure and cigarette smoking were found on mortality from lung cancer and all causes, which indicate that silica in combination with cigarette smoking accounts for a fraction of extra deaths. Therefore, more effective measures should be taken towards silica control and smoking cessation among iron mine workers.

\section{Abbreviations \\ CDE: Cumulative respirable silica dust exposure; Cl: Confidence interval; COPD: Chronic obstructive pulmonary disease; HR: Hazard ratio; ICD-10: The 10th version of the international classification of diseases; JEM: Job-exposure matrix; PAR: Population attributable risk; RERI: Relative excess risk due to interaction; SMR: Standardized mortality ratio}

\section{Acknowledgements}

We thank all the participants for their help.

\section{Funding}

This study was supported by the Fundamental Research Funds for the Central Universities, HUST 2016JCTD116. The funder did not participate in the research design, data collection, data analysis, and manuscript writing

\section{Availability of data and materials}

Please contact author for data requests.

\section{Authors' contributions}

HL, MZ, YZ, SW and WC contributed to study concept and design. HL, YL, TS, SW and WC contributed to data collection and interpretation. $\mathrm{HL}, \mathrm{YL}, \mathrm{MZ}$ and WC contributed substantially to the statistical analysis. All the authors have approved the manuscript and agree with submission to Occupational and Environmental Medicine.

\section{Ethics approval and consent to participate}

All participants in this study gave the written informed consents for participation. The methods were carried out in accordance with the relevant guidelines. This study protocol was approved by the Ethics and Human Subject Committee of Tongji Medical College, Huazhong University of Science and Technology, P. R. China.

\section{Competing interests}

The authors declare that they have no competing interests.

\section{Publisher's Note}

Springer Nature remains neutral with regard to jurisdictional claims in published maps and institutional affiliations.

\section{Author details}

'Department of Occupational and Environmental Health, School of Public Health, Tongji Medical College, Huazhong University of Science and Technology, 13 Hangkong Road, Wuhan 430030, Hubei, China. ${ }^{2}$ Key Laboratory of Environment and Health, Ministry of Education and Ministry of Environmental Protection, and State Key Laboratory of Environmental Health (Incubating), School of Public Health, Tongji Medical College, Huazhong University of Science and Technology, Wuhan 430030, Hubei, China. ${ }^{3}$ Hubei Provincial Key Laboratory for Applied Toxicology, Hubei Provincial Center for Disease Control and Prevention, Wuhan 430079, Hubei, China. ${ }^{4}$ Shenzhen Prevention and Treatment Center for Occupational Disease, Shenzhen, Guangdong, China.

Received: 14 January 2018 Accepted: 2 May 2018

Published online: 09 May 2018

\section{References}

1. Small C, Naumann T. The global distribution of human population and recent volcanism. Global Environmental Change Part B: Environmental Hazards. 2001;3:93-109.

2. Leung CC, Yu ITS, Chen W. Silicosis. Lancet. 2012;379:2008-18.

3. Chen W, Liu Y, Wang H, Hnizdo E, Sun Y. Su L, et al. long-term exposure to silica dust and risk of total and cause-specific mortality in Chinese workers: a cohort study. PLoS Med. 2012;9:e1001206.

4. Liu Y, Rong Y, Steenland K, Christiani DC, Huang X, Wu T, et al. Long-term exposure to crystalline silica and risk of heart disease mortality. Epidemiology. 2014;25:689-96.

5. Guo J, Shi T, Cui X, Rong Y, Zhou T, Zhang Z, et al. Effects of silica exposure on the cardiac and renal inflammatory and fibrotic response and the antagonistic role of interleukin-1 beta in C57BL/6 mice. Arch Toxicol. 2016;90:247-58.

6. Hnizdo E. Loss of lung function associated with exposure to silica dust and with smoking and its relation to disability and mortality in south African gold miners. Occup Environ Med. 1992;49:472-9.

7. Hnizdo E, Vallyathan V. Chronic obstructive pulmonary disease due to occupational exposure to silica dust: a review of epidemiological and pathological evidence. Occup Environ Med. 2003;60:237-43.

8. Ehrlich R, Churchyard G, Pemba L, Dekker K, Vermeis M, White N, et al. Tuberculosis and silica exposure in south African gold miners. Occup Environ Med. 2006;63:187-92.

9. Hnizdo E, Murray J. Risk of pulmonary tuberculosis relative to silicosis and exposure to silica dust in south African gold miners. Occup Environ Med. 1998:55:496-502.

10. Steenland K, Sanderson W. Lung cancer among industrial sand workers exposed to crystalline silica. Am J Epidemiol. 2001;153:695-703.

11. Pelucchi C, Pira E, Piolatto G, Coggiola M, Carta P, La Vecchia C. Occupational silica exposure and lung cancer risk: a review of epidemiological studies 1996-2005. Ann Oncol. 2006;17:1039-50.

12. Lacasse Y, Martin S, Gagné D, Lakhal L. Dose-response meta-analysis of silica and lung cancer. Cancer Causes Control. 2009;20:925-33.

13. Weiner J, Barlow L, Sjögren B. Ischemic heart disease mortality among miners and other potentially silica-exposed workers. Am J Ind Med. 2007;50:403-8

14. Zhang $H_{\text {, Cai }}$. The impact of tobacco on lung health in China. Respirology. 2003;8:17-21.

15. Peto R, Darby S, Deo H, Silcocks P, Whitley E, Doll R. Smoking, smoking cessation, and lung cancer in the UK since 1950: combination of national statistics with two case-control studies. BMJ. 2000;321:323-9.

16. Giovannucci E. An updated review of the epidemiological evidence that cigarette smoking increases risk of colorectal cancer. Cancer Epidemiology and Prevention. Biomarkers. 2001;10:725-31.

17. Huxley RR, Woodward M. Cigarette smoking as a risk factor for coronary heart disease in women compared with men: a systematic review and meta-analysis of prospective cohort studies. Lancet. 2011;378:1297-305. 
18. Ueshima H, Choudhury SR, Okayama A, Hayakawa T, Kita Y, Kadowaki T, et al. Cigarette smoking as a risk factor for stroke death in Japan. Stroke. 2004; 35:1836-41.

19. Laaksonen M, Rahkonen O, Karvonen S, Lahelma E. Socioeconomic status and smoking. Eur. J Pub Health. 2005;15:262-9.

20. Liu Y, Steenland K, Rong Y, Hnizdo E, Huang $X$, Zhang $H$, et al. Exposureresponse analysis and risk assessment for lung cancer in relationship to silica exposure: a 44-year cohort study of 34,018 workers. Am J Epidemiol. 2013;178:1424-33.

21. Chen J, McLaughlin JK, Zhang J-Y, Stone B, Luo J, Chen R-a, et al. Mortality among dust-exposed Chinese mine and pottery workers. J Occup Environ Med. 1992;34:311-6.

22. Dosemeci M, Chen JQ, Hearl F, Chen RG, McCawley M, Wu Z, et al. Estimating historical exposure to silica among mine and pottery workers in the People's Republic of China. Am J Ind Med. 1993:24:55-66.

23. Zhuang Z, Hearl F, Odencrantz J, Chen W, Chen B, Chen J, et al. Estimating historical respirable crystalline silica exposures for Chinese pottery workers and iron/copper, tin, and tungsten miners. Ann Occup Hyg. 2001;45:631-42.

24. Richardson DB, Kaufman JS. Estimation of the relative excess risk due to interaction and associated confidence bounds. Am J Epidemiol. 2009;169:756-60

25. Kinlen L, Willows A. Decline in the lung cancer hazard: a prospective study of the mortality of iron ore miners in Cumbria. Br J Ind Med. 1988;45:219-24.

26. Björ B, Burström L, Jonsson H, Nathanaelsson L, Damber L, Nilsson T. Fiftyyear follow-up of mortality among a cohort of iron-ore miners in Sweden, with specific reference to myocardial infarction mortality. Occup Environ Med. 2009;66:264-8.

27. Lawler AB, Mandel JS, Schuman LM, Lubin JH. A retrospective cohort mortality study of iron ore (hematite) miners in Minnesota. J Occup Environ Med. 1985;27:507-17.

28. Organization WH, Control RIT. WHO report on the global tobacco epidemic, 2008: the MPOWER package: World Health Organization; 2008.

29. Alberg AJ, Shopland DR, Cummings KM. The 2014 surgeon General's report: commemorating the 50th anniversary of the 1964 report of the advisory committee to the US surgeon general and updating the evidence on the health consequences of cigarette smoking. Am J Epidemiol. 2014;179:403-12.

30. Doll R, Peto R, Boreham J, Sutherland I. Mortality in relation to smoking: 50 years' observations on male British doctors. BMJ. 2004;328:1519.

31. Hunt D, Blakely T, Woodward A, Wilson N. The smoking-mortality association varies over time and by ethnicity in New Zealand. Int J Epidemiol. 2005;34:1020-8.

32. Müezzinler A, Mons U, Gellert C, Schöttker B, Jansen E, Kee F, et al. Smoking and all-cause mortality in older adults: results from the CHANCES consortium. Am J Prev Med. 2015:49:e53-63.

33. Adams JD, O'Mara-Adams KJ, Hoffmann D. Toxic and carcinogenic agents in undiluted mainstream smoke and sidestream smoke of different types of cigarettes. Carcinogenesis. 1987;8:729-31.

34. Vida S, Pintos J, Parent M-É, Lavoué J, Siemiatycki J. Occupational exposure to silica and lung cancer: pooled analysis of two case-control studies in Montreal, Canada. Cancer Epidemiol Biomark Prev. 2010;19:1602-11.

35. Suzuki N, Ohta K, Horiuchi T, Takizawa H, Ueda T, Kuwabara M, et al. T lymphocytes and silica-induced pulmonary inflammation and fibrosis in mice. Thorax. 1996;51:1036-42.

36. Guo J, Gu N, Chen J, Shi T, Zhou Y, Rong Y, et al. Neutralization of interleukin-1 beta attenuates silica-induced lung inflammation and fibrosis in C57BL/6 mice. Arch Toxicol. 2013;87:1963-73.

\section{Ready to submit your research? Choose BMC and benefit from:}

- fast, convenient online submission

- thorough peer review by experienced researchers in your field

- rapid publication on acceptance

- support for research data, including large and complex data types

- gold Open Access which fosters wider collaboration and increased citations

- maximum visibility for your research: over $100 \mathrm{M}$ website views per year

At BMC, research is always in progress.

Learn more biomedcentral.com/submissions 